\title{
Stable Gold Alloy Electrodeposits
}

\author{
John K. R. Page and Vivian G. Rivlin
}

Fulmer Research Institute, Stoke Poges, Buckinghamshire, England

\begin{abstract}
Gold-rich electrodeposits find extensive applications as electrical contacts, but material costs are forcing producer and user industries to give serious consideration to new methods of savings. Certain gold alloy electrodeposits, less than $10 \mu \mathrm{m}$, and usually $1 \mu \mathrm{m}$ thick, have remarkable stability to corrosion and diffusion, and may be valuable in ensuring prolonged contact life.
\end{abstract}

Electrical contact degradation in gold electrodeposits occurs by two separate but related processes that are well recognised: first by diffusion of the substrate (usually copper) through the gold to the surface of the electrodeposit where it is oxidised, and second by the oxidation of the substrate metal that is exposed either by porosity or by mechanical wear in service.

The achievement of a reputable method of porosity measurement is difficult (1) and to avoid failure from porosity it is normal to use either a minimum plating thickness, say $5 \mu \mathrm{m}$, or nickel underlayers which reduce the diffusion of substrate copper. These precautions can be very effective, but are expensive in material and involve additional inspection and processing steps.

Results are given below for the testing of gold alloy electrodeposits $1 \mu \mathrm{m}$ thick, with about 1 per cent base metal. Compared with pure unalloyed gold tested under the same conditions the alloys have high reliability and there are indications that alloying of gold can, to some extent, compensate for porosity and other defects in electrodeposits.

\section{Experimental Methods}

The work followed a standard format throughout. Copper discs, $13 \mathrm{~mm}$ in diameter and $6.5 \mathrm{~mm}$ thick, were polished to a reproducible finish and served as substrates for gold and gold alloy electrodeposition. Parallel series were also made with nickel under-layers. Most gold deposits were $1 \mu \mathrm{m}$ thick.

Specimen codings are as follows:

$$
\begin{aligned}
& 001 \quad 1 \mu \mathrm{m} \text { gold or gold alloy; no nickel } \\
& 011 \quad 1 \mu \mathrm{m} \text { gold or gold alloy; } 1 \mu \mathrm{m} \text { nickel } \\
& 101 \quad 1 \mu \mathrm{m} \text { gold or gold alloy; } 10 \mu \mathrm{m} \text { nickel }
\end{aligned}
$$

All specimens were plated four or five at a time in a machined brass jib which, when loaded, formed a planar equipotential surface in the plating bath. Pure gold was plated from an Engel- hard E55 bath (potassium gold cyanide) at 60 to $65^{\circ} \mathrm{C}, 290 \mathrm{~A} / \mathrm{m}^{2}, \mathrm{pH} 5$ to 6 and with high agitation by argon bubbling. A sulphamate solution served as the nickel plating bath.

Table I

Plating Procedures for Gold-Cadmium Alloys

\begin{tabular}{c|c|c|c}
\hline $\begin{array}{c}\text { Composition } \\
\text { cadmium } \\
\begin{array}{c}\text { weight per } \\
\text { cent }\end{array}\end{array}$ & $\begin{array}{c}\text { Current } \\
\text { density } \\
\mathrm{A} / \mathrm{m}^{2}\end{array}$ & $\begin{array}{c}\text { Temperature } \\
\text { C }\end{array}$ & Agitation \\
\hline 0.35 & 10.8 & 50 & $\begin{array}{c}\text { cathode } \\
\text { movement } \\
\text { ". }\end{array}$ \\
1.0 & 21.5 & 50 & ". \\
1.6 & 32.2 & 50 &
\end{tabular}

Gold-cadmium alloys were plated from a proprietary sulphite bath (Imasa Silvercrown Technigold 50). Preliminary deposits on copper foils were analysed by emission spectroscopy and the cadmium content was found to be a function of current density (Table 1). Two compositions were selected, 0.35 and 1.6 weight per cent cadmium and the plating procedure followed that set out in Table 1. Spot checks of individual disc specimens were carried out by $\beta$-probe spectrometry using a Telsec $\beta$-probe instrument at $10 \mathrm{kV}$ and $0.1 \mathrm{~mA}$. The relative signal ratios $\mathrm{Au} / \mathrm{Cd}$ showed very little drift within and between batches of the same nominal composition.

\section{Methods of Specimen Assessment}

For accelerated performance tests, samples were heated for up to a month in air at $200^{\circ} \mathrm{C}$. A corrosion test was provided by a static sulphur dioxide atmosphere with 1 to 2 per cent $\mathrm{SO}_{2}$ at over 90 per cent relative humidity in a desiccator (2). When not being tested, all samples were stored in plastic containers. 


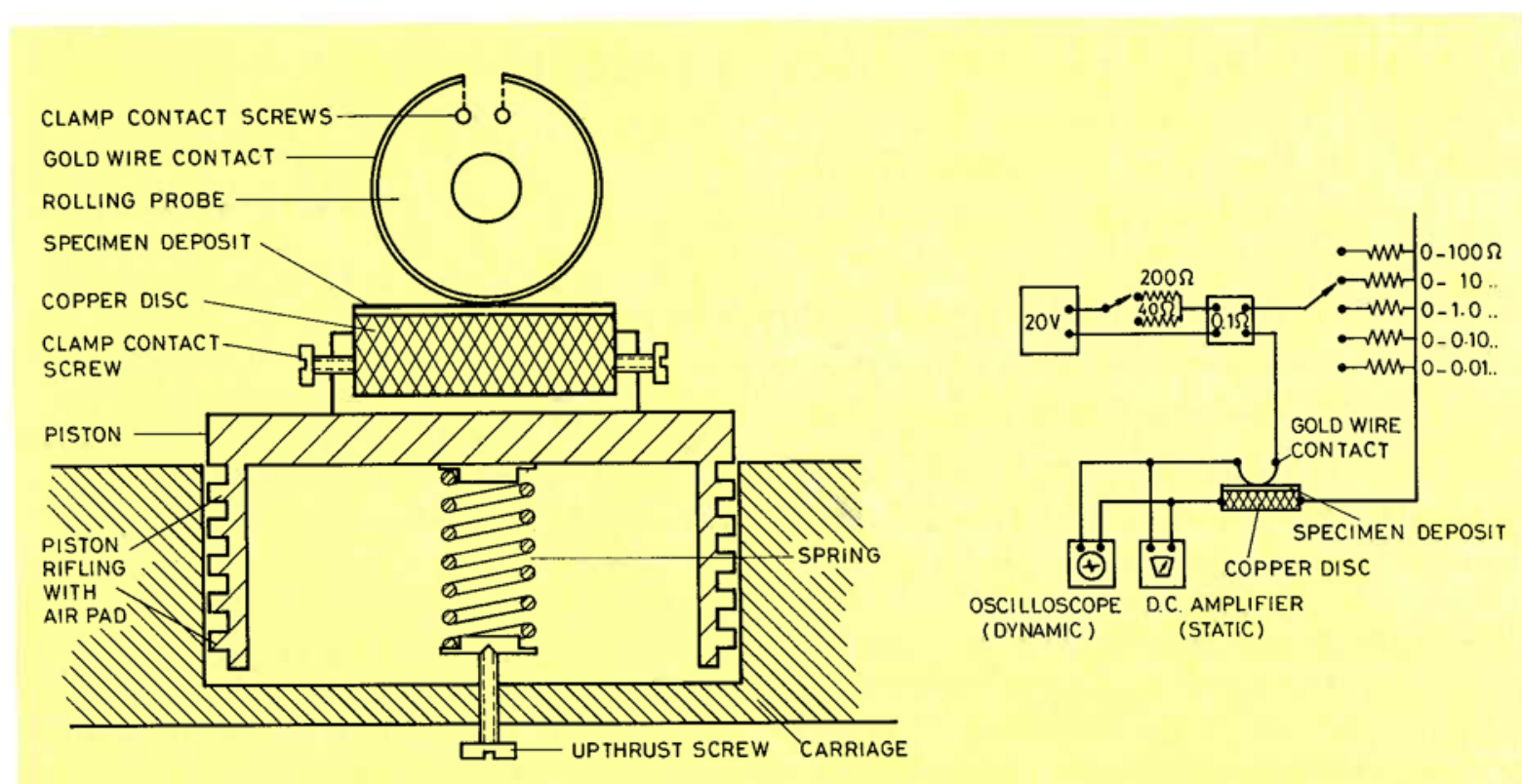

Fig. 1 Specimen mounting assembly and circuit used in this study for the measurement of both static and dynamic electrical contact resistance

\section{Porosity}

All the electrodeposits of thickness $1 \mu \mathrm{m}$ were porous. Analysis in the scanning electron microscope (Cambridge Stereoscan with EDAX microprobe attachment) showed randomly distributed cavities which invariably gave enhanced copper signals with the point probe. Apart from these cavities no other features were noticed in the electrodeposits prior to going on test. An incidental point of interest is the occasional recording of strong silicon signals from the pores, attributed to $\mathrm{SiC}$ abrasive embedded in the copper substrate. It is commonly assumed that $\mathrm{SiC}$ inclusions, being relatively non-conducting, are one source of pores $(3,4,5)$. At a deposit thickness of $1 \mu \mathrm{m}$ these pores were frequent, at $2 \mu \mathrm{m}$ and over (see below) they were covered by overplating.

The porosity inherent in thin deposits required a rapid non-destructive method of measurement suited to batch analysis. This was available from an image analysing computer (Quantimet 720) linked to a high magnification optical microscope. The results gave reproducible counts of pore density, size distribution (mainly $1 \mu \mathrm{m}$ in diameter) and pore area. The latter was measured as a percentage of the sample area scanned, and systematic measurements for gold and gold alloy deposits $1 \mu \mathrm{m}$ thick gave pore areas of about 0.5 to 1 per cent. Increasing the thickness of the deposit or the introduction of a nickel underlayer diminished pore areas by at least an order of magnitude.

\section{Contact Resistance}

The electrical contact resistance, $R_{c}$, was measured with a pure gold wire probe, $0.5 \mathrm{~mm}$ in diameter, fitted to the rim of a rolling wheel and under a $50 \mathrm{~g}$ load. The apparatus, shown schematically in Figure 1, gave a means of measuring $R_{c}$ at any site on the surface of the deposit, using either static or dynamic recording. The static method gave $R_{c}$ to a maximum sensitivity of $0.2 \mathrm{~m} \Omega$ without mechanical rupture of the insulating oxide films developed on test. Electrical breakdown was avoided by limiting the open-circuit voltage to $10 \mathrm{mV}$. At least five sites were measured on each of three different diameters. Dynamic readings recorded on an oscilloscope gave the instantaneous $\mathrm{R}_{\mathrm{c}}$; however static measurements were considered more convenient for long-term tests of response to heat-treatment.

\section{Corrosion Creep}

The development of corrosion was followed using marker grooves notched into the gold or gold alloy electrodeposit. The corrosion products were easily visible to the naked eye and surrounded each groove as a roughly rectangular stain. Microprobe analysis revealed an enhanced copper signal from the stain; traces of sulphur were found in the neighbourhood of the grooves. A quantitative estimate of the magnitude of corrosion creep was made as follows by means of the image analysing computer: the grooves were scanned along their length and the computer print-out 
Table II

Effect of Heat Treatment in Air on the Mean Contact Resistance $R_{c}$ (in $\mathbf{m} \Omega$ ) of Gold Electrodeposits

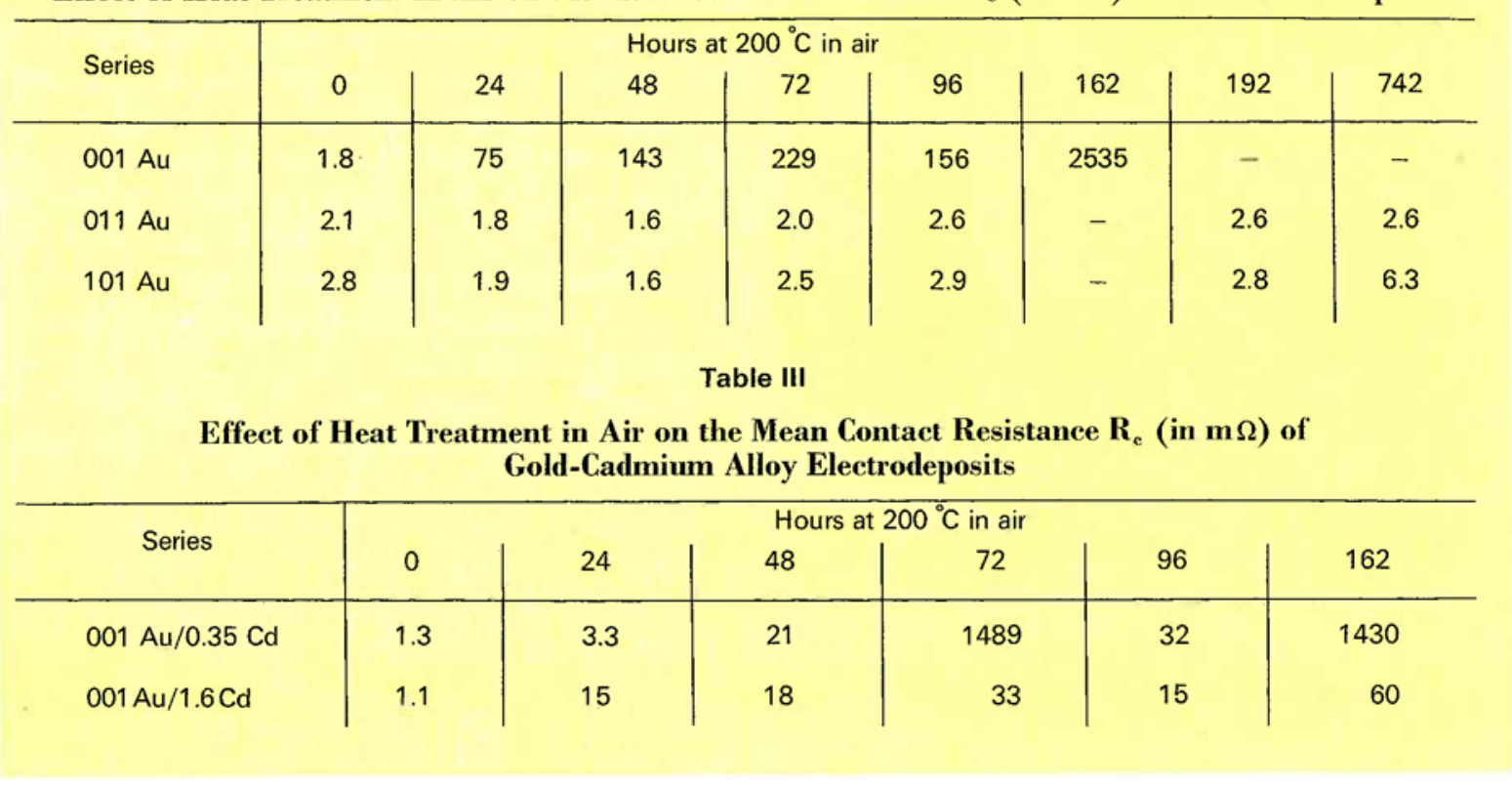

presented the extent of creep in terms of the total number of times which the corrosion product exceeded selected creep distances. The counts, $\mathrm{N}_{\mathrm{c}}$, are cumulative and when presented as percentages, per cent $N_{c}$, they are by definition 100 at the groove axis and zero at the maximum creep distance. Reproducible results were obtained when per cent $\mathrm{N}_{c}$ was plotted against creep, and were quite distinctive for each of the different alloy series.

\section{Surface Compositions}

Routine microprobe analyses gave assessments of bulk deposit and substrate compositions before and after accelerated testing. However, the most significant observations were made by means of techniques more representative of the first few monolayers of the electrodeposit : electron spectroscopy for chemical analysis or ESCA (6) and ion scattering spectroscopy or ISS (7). An AEI ES100 instrument with $\mathrm{A} 1 \mathrm{~K} \alpha \mathrm{X}$-rays (energy $1486.6 \mathrm{eV}$ ) was used to obtain ESCA spectra standardised against the gold $4 \mathrm{f} 7 / 2$ and $4 \mathrm{f} 5 / 2$ peaks, taken to correspond to binding energies of 86.5 and $82.8 \mathrm{eV}$ respectively. The data are representative of surface layers estimated to be 1 to $3 \mathrm{~nm}$ in thickness (6). Ion scattering spectra were obtained using rare gas ions. Each scan represents the top-most monolayer, but the ion etching facility in ISS allows depth profiles to be determined by the etching away of successive monolayers.

\section{Results}

The variation of contact resistance with time in air at $200^{\circ} \mathrm{C}$ is given in Table II for gold on copper (001 Au series) and for gold with a nickel under-layer on copper (011 Au and $101 \mathrm{Au}$ series).

The presence of a nickel underlayer ( 1 or $10 \mu \mathrm{m}$ ) improves stability to the extent that very low contact resistance and a bright appearance are retained after four weeks at $200^{\circ} \mathrm{C}$. By contrast gold on copper alone rapidly becomes strongly discoloured and high $R_{c}$ values develop.

Parallel measurements on gold-cadmium alloys on copper (001 series) gave the results shown in Table III. Comparison with the results for pure gold on copper in Table II shows a marked improvement in the response to accelerated tests. The initial contact resistance is unaffected by alloying and a low value is retained after almost one week at $200^{\circ} \mathrm{C}$ for the higher cadmium content. The appearance of the films is quite bright for this series, as illustrated in Figure 2. The development of resistive surface films has been significantly retarded by inclusion of cadmium.

Corrosion creep measurements for the 001 series of gold and gold-cadmium are shown in Figure 3. The results indicate the gold alloys to be more stable to creep and, as with the heat-treatment tests, stability seems to be a function of cadmium content. The results have been confirmed by duplicate runs. In practical terms the fact that the per cent $N_{c}$ parameter with gold exceeds that with the alloys means that corrosion creep is 


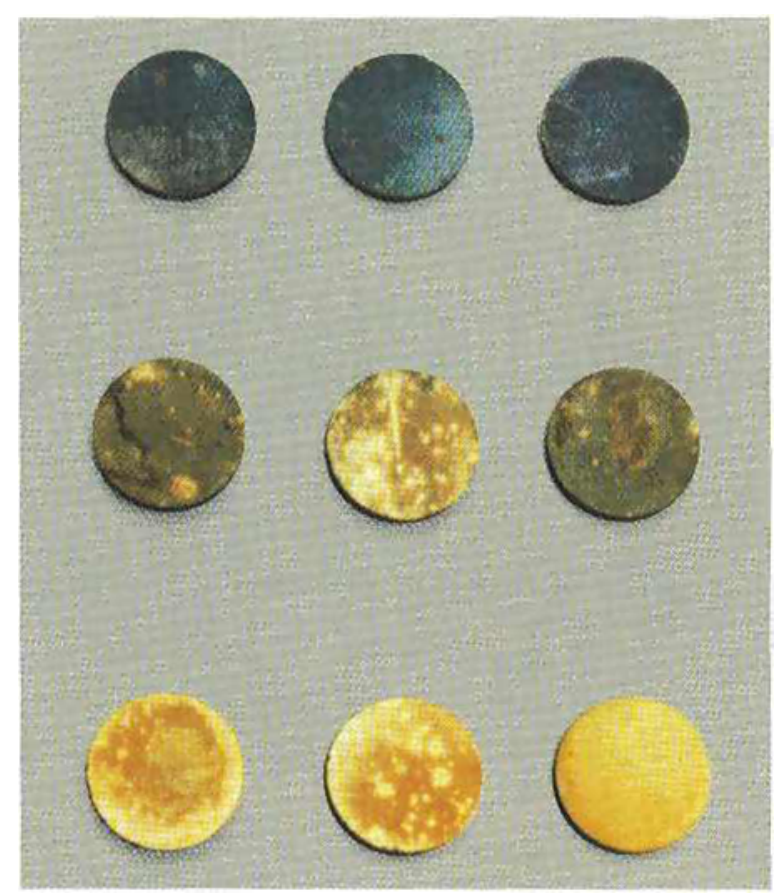

Fig. 2 Appearance of gold and gold-cadmium electrodeposits in the 001 series after heat-treatment in air for 162 hours at $200{ }^{\circ} \mathrm{C}$

\section{Top: Pure gold \\ Centre: Gold $/ 0.35$ cadmium \\ Bottom: Gold/1.6 cadmium}

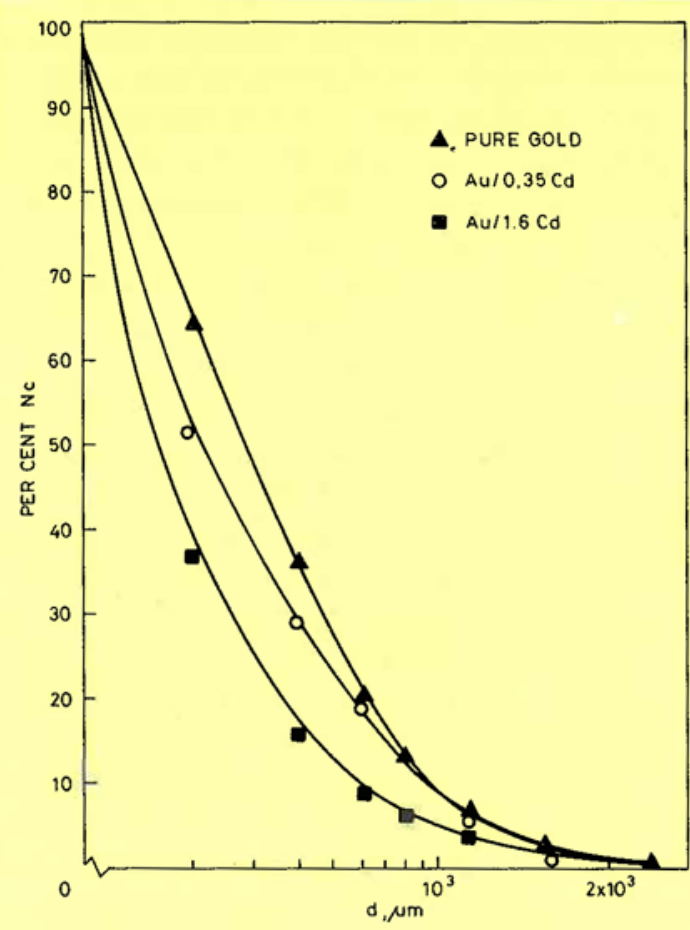

Fig. 3 Corrosion creep of sulphur products after 24 hours in $\mathrm{SO}_{2}$ at room temperature. Gold electrodeposit on copper substrate with no nickel underlayer (001 series) retarded by alloying. Thus at a creep distance of about $200 \mu \mathrm{m}$ the per cent $N_{c}$ values are as follows:

$\begin{array}{llcc}001 \text { series } & \mathrm{Au} & \mathrm{Au} / 0.35 \mathrm{Cd} & \mathrm{Au} / 1.6 \mathrm{Cd} \\ \text { per cent } \mathrm{N}_{\mathrm{c}} & 64 & 52 & 37\end{array}$

A similar comparison of gold and gold-cadmium electrodeposit in the 101 series again showed creep to have been retarded in the alloys although in this case no composition dependence emerged and the per cent $\mathrm{N}_{\mathrm{c}}$ curves of gold $/ 0.35$ cadmium and gold/1.6 cadmium were superposed and well below that of pure gold. In all cases creep in 101 specimens was smaller than for 001 specimens, as might be expected.

ESCA scans of the 001 series (both pure gold and gold-cadmium electrodeposits) before and after exposure for 162 hours at $200^{\circ} \mathrm{C}$ proved that the presence of small amounts of cadmium retards copper diffusion. The scans, illustrated in Figure 4 show a strong copper signal from the pure gold electrodeposit, while the addition of 0.35 and 1.6 weight per cent cadmium respectively lowers and suppresses it. ISS scans of the same samples (Figure 5) show that after preliminary ion etching to remove surface impurities (such as organic film) the pure gold electrodeposit has a strong copper signal but the signal for gold itself is very weak. The reverse is true for the gold cadmium alloy (in this case gold/1.6 per cent cadmium). Further etching, about 15 atomic layers, makes little difference to the pure gold electrodeposit for which by far the strongest signal is from copper. The goldcadmium, on the other hand, now has very little copper and is largely gold with a trace of cadmium.

These experiments are evidence that after prolonged heat-treatment the pure gold electrodeposits are saturated with copper to a depth of at least 15 monolayers. The presence of cadmium in small amounts retards copper diffusion, which is detected only in small quantity and mainly on the first few monolayers.

Attempts were made to follow the development of copper diffusion on pure gold using the point probe attachment on the scanning electron microscope. A selected pure gold electrodeposit was measured before and after heat-treatment at $200^{\circ} \mathrm{C}$ for 24, 48, 72 and 96 hours. Both gold and copper signals were observed from the start; the copper signal originated from the substrate as a result of penetration by the point probe bearn through the gold electrodeposit. However, as the heattreatment time increased, there was evidence that the intensity of the copper signal (measured relative to that of gold) increased by some 50 per cent and that there was no preferential accumulation of copper round the pores. These results must be viewed with caution since changes in sig- 
Fig. A Electron Sjectroseopy for Cherrieal Anaylisi (ESCA) some of goll and gold-cadmium deposits hoalEreated 162 howr in $200^{\circ} \mathrm{C}: \mathrm{in}$ air

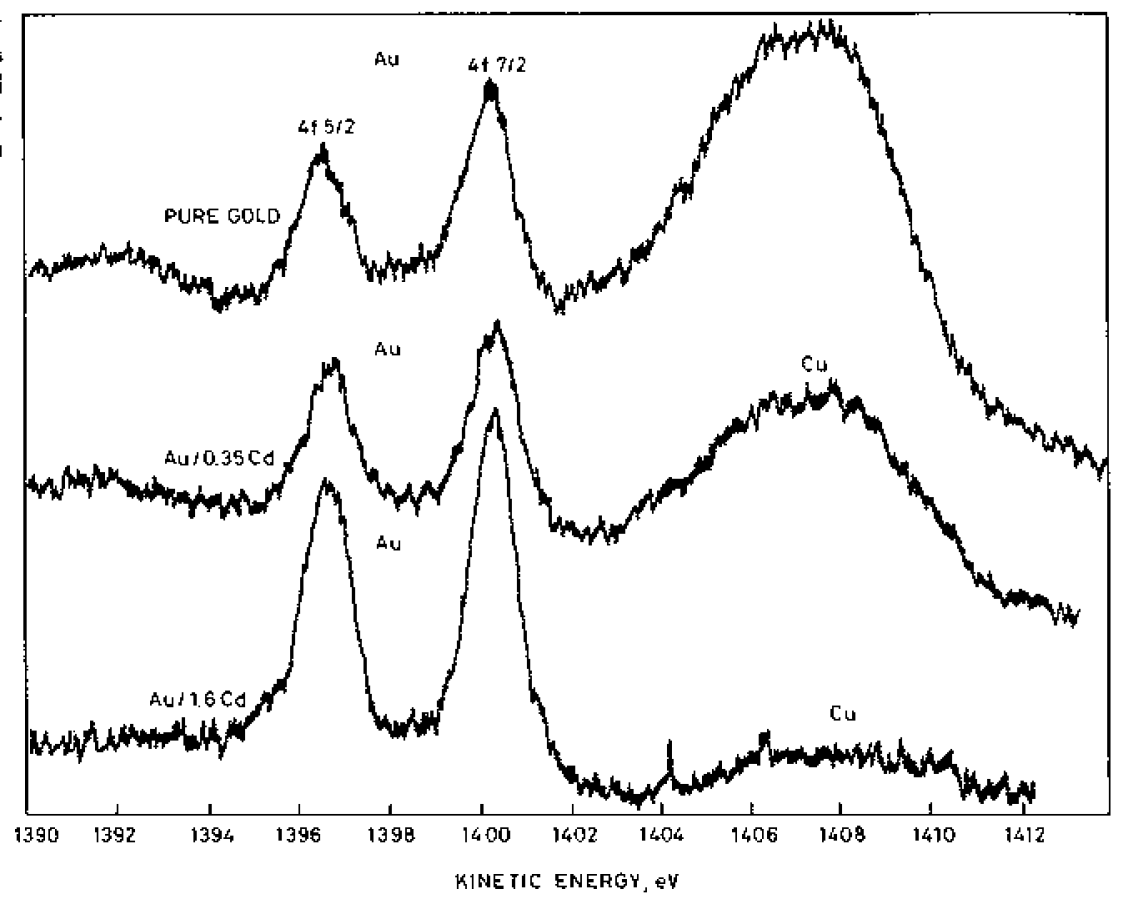

nal strength may be infucneed by incidental factors such as ripples on the surface of the deposit. Nevertheless, their consistency suggests that the development of copper films on gold during heattreatment is determined by diffusion through the gold deposits rather than diffusion via pores.

Examination of pure gold electrodeposits of the 011 and 101 series by the point probe method gave no evidence of any accumulation of nickcl on the plating surface. ESCA scans, however, did reveal traces of nickel together with even smaller traces of copper after 742 hours ( 1 month) at $200^{\circ} \mathrm{C}$.

\section{Discussion}

Diffusion in copper-thin gold film couples has been the subject of numerous studies which have yielded divergent values for the diffusion coefficient $D_{0}$ and activation energy $Q$ depending partly on the experimental temperature range and partly on the nature of the thin films investigated Recent work by Pinnel and Bennett on copper diffusion in gold electrodeposits (8) and on the effect of nickel under-layers (9) provides a convenicnt starting point. Pinnel and Bennett find a close agreement between their measurements

Fig. 5 Ion Seatering Speetroseopy (ISS) seans of gold and gadd-cadminm drposits heat -treatrol 162 lours at $200^{\circ} \mathrm{C}$ in ait. Fourde monelayor: 20 minutes celling with ${ }^{4}$ He. liffeenth monnlayer: prolonged eteling with "Hes " $\mathrm{Ne}$ and ${ }^{0} \mathrm{Ar}$

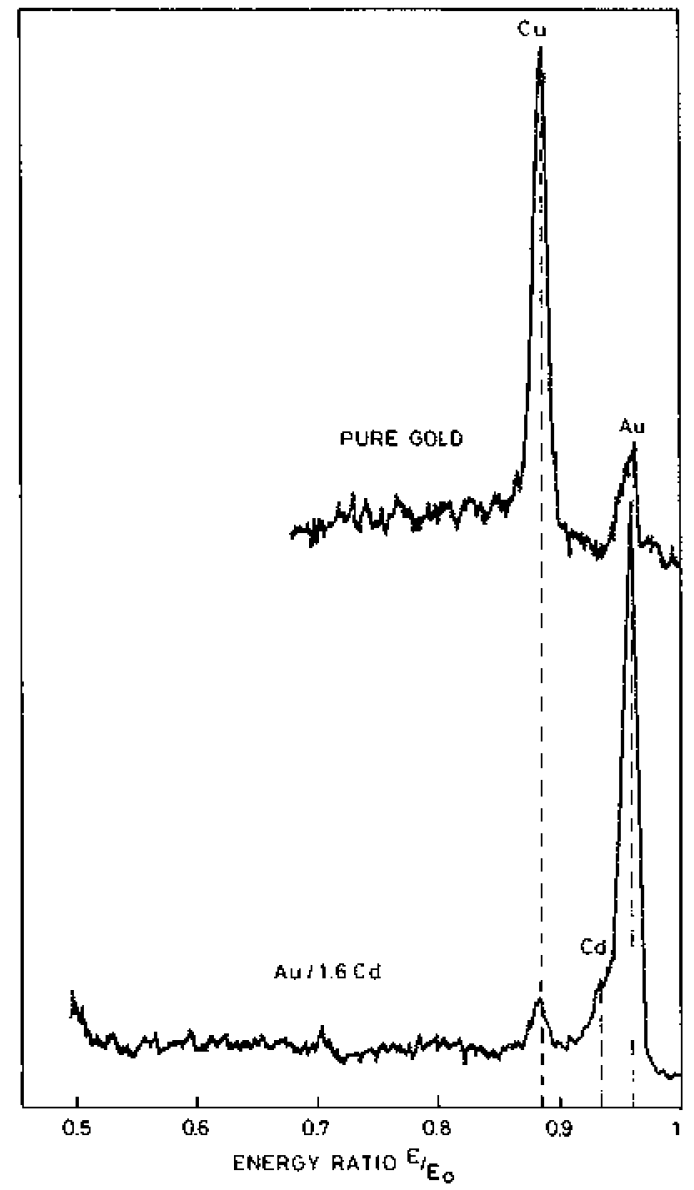


and those of earlier workers in the temperature range 250 to $750^{\circ} \mathrm{C}$ and the kinetics are associated with volume diffusion. At lower temperatures (50 to $250^{\circ} \mathrm{C}$ ) a lower apparent energy of activation value is interpreted in terms of defect diffusion mechanisms where grain boundaries, dislocation pipes, etc., play a prominent part. The transition is believed to be between 150 and $250^{\circ} \mathrm{C}$, above which range rapid annealing of the defects is postulated.

The importance of a postulated defect annealing mechanism in the vicinity of $200^{\circ} \mathrm{C}$ to results in this paper is that one would expect the diffusion of copper to be determined, at least in part, by interactions between copper atoms and vacancies in the gold lattice.

The role of traces of cadmium in impeding copper diffusion is speculative but observations of this type are not new. Ageing reactions in aluminium/4 per cent copper have been studied extensively at the Fulmer Research Institute, and decreases in ageing kinetics by one order of magnitude have resulted from the inclusion of less than 1 per cent cadmium, indium, tin or antimony $(10,11)$. The greater affinity of the trace element than of copper for lattice vacancies is commonly assumed to be the reason for the retardation of the ageing reaction. Lattice strains introduced by the disparity in atomic sizes between trace element and matrix atoms may create localised 'vacancy sinks' which attract and immobilise vacancies and other defects, thereby reducing the matrix defect concentration and increasing the length of time needed for a matrix reaction to take place.

If this interpretation is applied to the experiments reported in this paper, it may be argued that the cadmium has effectively reduced the vacancy concentration in the gold matrix and, consequently, copper migration is compelled to take place by a much slower lattice diffusion mechanism. This interpretation suggests that a number of other elements are of interest as trace additives to gold since their atomic diameters (taken as equal to the mean closest distance of approach between atoms in the elemental state) are larger than that of gold $(2.88 \AA)$.

Additives to be considered are:

$\begin{array}{lccc}\begin{array}{l}\text { Element } \\ \text { Atomic }\end{array} & \mathrm{Cd} & \mathrm{Sn}(\beta) & \mathrm{Sb} \\ \text { diameter, } \AA & 2.98 & 3.02 & 2.90 / 3.46\end{array}$

Other elements of potential interest include: In

$(3.25 \AA), \mathrm{Hg}(3.01 \AA), \mathrm{Tl}(3.41 \AA), \mathrm{Pb} 3.50 \AA)$, Bi (3.11 $\AA$ ).

Preliminary experiments have been carried out with tin and antimony. The alloy compositions were between 1 and 2 weight per cent, but the quality of the deposits left much to be desired and electrical resistance values were not encouraging. Nevertheless, using ESCA as a guide, the spectra again showed some retardation of copper diffusion and the electrodeposits retained their brightness after prolonged heat-treatment in air at $200^{\circ} \mathrm{C}$. Furthermore, there is some evidence that both tin and antimony enhance the resistance to corrosion creep on gold in a $\mathrm{SO}_{2}$ atmosphere.

The interpretation of the role of cadmium and other trace elements relies on the assumption that the defect density in gold and gold alloy deposits is comparable. This is not necessarily true in view of the fact that the deposits are made from a variety of electroplating solutions. The above experiments have therefore been supplemented by similar tests on pure gold and gold-cadmium deposits, $1 \mu \mathrm{m}$ thick, prepared independently under standardised conditions by Imasa Ltd. . The solutions used were Technigold 25 and Technigold 50 (pure gold and gold-cadmium respectively). The response to heat-treatment of the $1 \mu \mathrm{m}$ deposits prepared by Imasa established a pattern quite similar to that given above for the Fulmer specimens, although the heat-treatment period at $200^{\circ} \mathrm{C}$ was about twice as long, indicating a better overall quality of deposits. This and other observations, which it is hoped will be published in due course, reinforce the case for an accurate comparison of the effects of different alloying elements in gold.

The practical applications of the effects which are reported in this article have been the subject of a patent (12).

\section{Acknowledgements}

This work was supported by the Chamber of Mines of South Africa and the International Gold Corporation Limited and the authors would like to thank Dr. W. S. Rapson and Dr. T. Groenewald for their interest and encouragement. Thanks are also due to Mr. W. A. Fairweather and Dr. J. Russell House of Imasa Silvercrown Limited for providing specimens and for helpful discussions.

\section{References}

1 J. M. Leeds and J. R. Townley, Met. Finısh. F., 1972, 18, $(210), 190$

2 British Standard 1615.1961

3 S. M. Garte, Plat. Surf. Finish., 1968, 55, 946

4 G. L. Cooksey and H. S. Campbell, Trans. Inst. Met. Finish., 1970, 48, 93

5 M. Clarke and A. M. Chakrabarty, Trans. Inst. Met. Finish., 1972, 50, 11

6 S. H. Hercules and D. M. Hercules, in 'Characterisation of Solid Surfaces', ed. by P. F. Kane and G. B. Larrabee, Plenum Press, New York-London, 1974, 307-336

7 D. P Smith, Surf. Sci., 1971, 25, 171

8 M. R. Pinnel and J. E. Bennett, Metal. Trans., 1972, 3, 1989

9 M. R. Pinnel and J. E. Bennett, Metal. Trans., 1976, 7A, 629

10 J. M. Silcock, Phil. Mag., 1959, 4, (46), 1187

11 G. B. Brook, 'Precipitation in Metals', Special Report No. 3 A review of work at the Fulmer Research Institute, 1947 1963

12 British Patent 1461474 